\title{
Lack of vulnerability segmentation in four angiosperm tree species: evidence from direct X-ray microtomography observation
}

\author{
Ximeng $\mathrm{Li}^{1} \cdot$ Sylvain Delzon ${ }^{2} \cdot$ Jose Torres-Ruiz ${ }^{3} \cdot$ Eric Badel $^{3} \cdot$ Regis Burlett $^{4} \cdot$ Hervé Cochard $^{3} \cdot$ Steven Jansen $^{5}$. \\ Andrew King $^{6} \cdot$ Laurent J. Lamarque $^{4} \cdot$ Nicolas Lenoir $^{2} \cdot$ Nicolas Martin St-Paul $^{3} \cdot$ Brendan Choat $^{1}$
}

Received: 15 November 2019 / Accepted: 12 March 2020 / Published online: 31 March 2020

(C) INRAE and Springer-Verlag France SAS, part of Springer Nature 2020

\begin{abstract}
- Key message Xylem vulnerability to drought-induced embolism did not differ between stems and petioles of four woody species (Betula pendula, Liriodendron tulipifera, Populus tremula and Olea europaea). Our results, together with data compiled from published literature, indicate that hydraulic segmentation during drought stress is not consistently driven by difference in vulnerability to embolism between stem and terminal organs.

- Context Hydraulic failure and disconnection of distal organs during protracted drought stress is thought to protect large branches or trunks by reducing water loss and restricting the spread of embolism. Hydraulic segmentation and preferential sacrifice of distal organs such as leaves can be driven by two mechanisms: more negative water potentials at the terminal section of the hydraulic pathway and/or by higher vulnerability to xylem embolism of distal organs. Although vulnerability segmentation has been reported in the literature, the generality of this phenomenon is unclear, in part due to the methodological limitations related to direct measurement of xylem vulnerability to embolism in intact plants.

- Aims The objective of this study was to evaluate vulnerability segmentation between petioles and stems using non-invasive micro computed tomography (microCT).

- Methods Vulnerability to embolism was measured in leaf petioles and subtending stems of four woody species (Betula pendula R., Liriodendron tulipifera L., Populus tremula L. and Olea europaea L.) with contrasting drought tolerances. In addition,
\end{abstract}

Handling Editor: Erwin Dreyer

Contribution of the co-authors Conceptualization: Brendan Choat; Formal Analysis: Ximeng Li, Brendan Choat, Jose Torres-Ruiz, Sylvain Delzon; Investigation: all co-authors; Data curation: Ximeng Li; Writingoriginal draft: Ximeng Li; Writing review and editing: all co-authors; Funding acquisition: Brendan Choat

Brendan Choat

B.Choat@westernsydney.edu.au

Ximeng Li

liximeng2009@hotmail.com

Sylvain Delzon

pujoulade@gmail.com

Jose Torres-Ruiz

torresruizjm@gmail.com

Eric Badel

eric.badel@inra.fr

Regis Burlett

regis.burlett@u-bordeaux.fr

Hervé Cochard

herve.cochard@inra.fr
Steven Jansen

steven.jansen@uni-ulm.de

Andrew King

king@synchrotron-soleil.fr

Laurent J. Lamarque

llamarqueab@gmail.com

Nicolas Lenoir

nicolas.lenoir@3sr-grenoble.fr

Nicolas Martin St-Paul

nico09.martin@gmail.com

Extended author information available on the last page of the article 
previously published vulnerability data for petioles and stems were compiled from the literature to investigate the commonality of hydraulic segmentation across a wide range of woody species, with the vulnerability curve methodology distinguished.

- Results Using non-invasive imaging on intact plants, we found no evidence of hydraulic segmentation between petioles and stems of four angiosperm tree species, regardless of mechanism. Moreover, the literature dataset indicated that little or no difference in vulnerability to embolism is present between petioles and stems when vulnerability curves were constructed using methods specifically measuring the dynamics of xylem tissue during dehydration (e.g. optical visualization, MicroCT).

- Conclusion Our results suggest that vulnerability segmentation between stems and distal organs (petioles and leaves) is limited when only xylem tissue is considered. Large differences in vulnerability between stems and leaves are likely to be driven by extra-xylary components, rather than xylem embolism.

Keywords Embolism $\cdot$ Hydraulic segmentation $\cdot$ microCT $\cdot$ Petiole $\cdot$ Stem $\cdot$ Xylem

\section{Introduction}

Water transport along the soil-plant-atmosphere continuum (SPAC) requires a minimal input of metabolic energy from the plant but entails a risk of hydraulic failure that increases with drought stress. Energy provided by solar radiation drives evaporation from within the leaf to the air, which leads to the generation of strong surface tension forces in mesophyll cell walls. The high tensile strength of liquid water allows this tension to be transmitted from the leaves to the roots where it acts to draw water from the soil (Dixon and Joly 1895; Zimmermann 1983). As such, liquid water in the xylem is under tension and is prone to cavitation and formation of gas emboli. Drought-induced embolism, which refers to the blockage of xylem conduits by gas bubbles, occurs when xylem tensions exceed critical thresholds required to cause air seeding and cavitation (Sperry and Tyree 1988; Cochard et al. 1992; Delzon et al. 2010). As embolized vessels can no longer conduct water, the spread of emboli within the vascular system compromises leaf gas exchange (Hubbard et al. 2001) and may lead to organ, tree or whole stand mortality in extreme cases (Barigah et al. 2013; Choat et al. 2018). Vulnerability to embolism is a key functional trait shaping the distribution of woody species at regional or local scales (Brodribb and Hill 1999; Engelbrecht et al. 2007; Trueba et al. 2017; Oliveira et al. 2019), and is the primary determinant of survivorship when plants are subjected to severe drought (Blackman et al. 2009; Brodribb and Cochard 2009; Urli et al. 2013; Anderegg et al. 2016).

Plants have developed a diverse range of strategies to mitigate the impact of water stress and reduce the probability of catastrophic xylem embolism. One such strategy is the segmentation of the hydraulic pathway in order to protect the major organs necessary for the survival of the tree such as the trunk. The hydraulic segmentation hypothesis was proposed more than 30 years ago when hydraulic maps and pressure profiles within trees were delineated (Zimmermann 1983). This hypothesis states that peripheral organs, which represent a low carbon investment for many woody species, will be hydraulically isolated during stress in order to minimize water loss from transpiration and compartmentalize embolism, thereby protecting more proximal organs (stems or trunk) that represent a larger carbon investment (Tyree and Ewers 1991). According to the original interpretation, segmentation is primarily facilitated by the increased xylem pressure gradients towards the terminal sections of the hydraulic pathway as distal organs often exhibit higher hydraulic resistance (Yang and Tyree 1994; Sack and Holbrook 2006). In contrast, the vulnerability segmentation hypothesis, introduced by Tyree and Ewers (1991), posits that segmentation may occur because the xylem of distal organs is more vulnerable to embolism than that of basal organs (Tyree and Ewers 1991; Tyree et al. 1993; Pivovaroff et al. 2014; Zhu et al. 2016). These hypotheses are not mutually exclusive since differences in organ vulnerability are not required for segmentation under the hydraulic segmentation hypothesis. However, a detailed understanding of mechanisms leading to hydraulic segmentation is important and has implications for predicting plant response to drought, e.g. is vulnerability segmentation universal across woody species such that leaves are shed earlier during drought because they are less resistant to embolism?

Experimental studies testing the segmentation and vulnerability segmentation hypotheses have produced inconsistent results, which could in part arise from methodological discrepancies when the cause of hydraulic decline of different organs is examined. Much of the previously published literature measuring hydraulics characteristics of different organs indicates that leaves and petioles are generally more vulnerable to embolism than stems, thus providing evidence in support of the vulnerability segmentation hypothesis (Tyree et al. 1993; Choat et al. 2005; Pivovaroff et al. 2014; Nolf et al. 2015; Johnson et al. 2016). However, vulnerability curves used for these comparisons have been generated using a wide range of techniques and this causes some complications for interpretation (Cochard et al. 2013; Trifilo et al. 2014; Torres-Ruiz et al. 2015a, b). Hydraulic techniques used for generation of leaf vulnerability curves incorporate water conducting tissues outside of the xylem, making it difficult to disentangle the contributions of xylary and extra-xylary pathways. Recent evidence suggests the extra-xylary pathways suffer significant loss of conductance before any cavitation occurs in the leaf 
vasculature (Scoffoni et al. 2017; Corso et al. 2020). It is therefore important to separate loss of extra-xylary conductance from vulnerability to embolism in this context. This is especially relevant considering that extra-xylary components are likely far more dynamic and rapidly recoverable than losses in xylary conductance induced by cavitation; there is not a clear consensus regarding the capacity of embolism repair to facilitate rapid recovery of xylem conductance post stress (Charrier et al. 2016; Lamarque et al. 2018).

Non-invasive imaging techniques (e.g. MRI, microCT, optical technique) have the advantage of avoiding artefacts that may occur with destructive methodology and allow for measurements to be made simultaneously on different organs within an intact plant (Cochard et al. 2013; Brodribb et al. 2016). They also allow the impacts of xylem cavitation to be examined separately from changes in extra-xylary conductance, thus providing a clearer understanding of the mechanisms underpinning plant response to drought. Recent studies incorporating in vivo observation of xylem function during dehydration with non-invasive imaging techniques suggest that differences in vulnerability to embolism between organs may have been overestimated in previous work (Bouche et al. 2016; Skelton et al. 2017, 2018; Rodriguez-Dominguez et al. 2018), although some studies utilizing non-invasive techniques found petioles are more vulnerable to embolism than stems in grapevine (Charrier et al. 2016; Hochberg et al. 2016). These contrasting findings highlight the need for further observations using noninvasive techniques in order to resolve questions surrounding the segmentation and vulnerability segmentation hypotheses and to determine the degree of variation in hydraulic strategies employed by different plant functional groups.

Here we report on the xylem vulnerability to embolism of petioles and stems for four angiosperm tree species that are known to have contrasting drought tolerance, with the aim of testing the hydraulic segmentation hypothesis. Vulnerability curves of petioles and stems were generated simultaneously from intact plants using synchrotron-based high-resolution microCT. The application of one technique to different organs avoids potential bias associated with using different techniques for each organ. Vulnerability to drought was quantified as the water potential inducing $50 \%$ loss of xylem conductivity $\left(\mathrm{P}_{50}\right)$. Given the results of recent studies utilizing non-invasive imaging, we hypothesized that petioles and stems would show similar $\mathrm{P}_{50}$ and rates of embolism formation during drought.

\section{Material and methods}

\subsection{Plant material}

Four angiosperm tree species were selected for the study: three temperate deciduous species (Betula pendula Roth, Liriodendron tulipifera L. and Populus tremula L.) and one evergreen species (Olea europaea L. cv. Arbequina). All tree species are diffuse-porous. The temperate deciduous species (B. pendula, L. tulipifera and P. tremula) were sourced from the INRAE nursery (Pierroton, France) and grown in 5-L pots under well-watered conditions at the University of Bordeaux (France). Plants were 3-4 years old and $1.0-1.5 \mathrm{~m}$ in height. For O. europaea, 2 3-year-old saplings were obtained from a nursery in Spain (Iberplant Jardineria i Vivers SL, Spain), repotted into 1.5 -L pots and grown for two months under well-watered conditions at the University of Bordeaux.

\subsection{Measurement of vulnerability to embolism by X-ray microCT imaging}

Synchrotron-based X-ray microtomography was used to estimate vulnerability to drought-induced embolism in the main stems and petioles of the four target species. Experiments took place over two allocations of beamtime in April 2015 and May 2016. At the microCT beamline (PSICHE) of the SOLEIL synchrotron facility (Saclay, France), plants were transported by road to the synchrotron just prior to beamtime in each year. The temperate deciduous species were dehydrated naturally over the course of five days, with three to five replicate plants of each species used for observations of vulnerability to embolism (B. pendula: $n=5 ; L$. tulipifera: $n=$ 3; P. tremula: $n=3$ ). Plants were initially placed outside of the synchrotron in full sunlight to dry. During the final phase of drying, plants were removed from pots to increase the rate of dehydration. A different protocol was used for $O$. europaea because of longer the time required for dehydration. A subset of plants $(n=5)$ was progressively dehydrated during a 10 day period leading up to the beamtime, with a second set of plants maintained in a well-watered condition until the beamtime commenced and then dehydrated naturally over the course of five days. In total, twelve replicate plants were used for observations of vulnerability to embolism in O. europaea.

Two hours before each scan, one leaf per plant was wrapped in a plastic bag and covered with aluminium foil in order to allow for equilibrium between the leaf and stem and provide accurate measurements of stem xylem water potential $\left(\Psi_{\mathrm{x}}\right)$. Water potential was measured immediately after the scan with a Scholander pressure chamber (Precis 2000, Gradignan, France). The PSICHE beamline has a hollow rotary stage configuration, which permits plants to be scanned at different heights (e.g. basal and apical portions). Petioles attached to mature, fully expanded leaves close to the top of the stem were scanned by placing a potted plant in hollow rotary stage. Immediately following this, the height of the stage was raised allowing the main stem axis to be scanned. In some cases, petioles and stems were scanned together by affixing a leaf to the stem using adhesive tape. Scans were made using a high flux $\left(3.10^{11}\right.$ photons.mm $\left.{ }^{-2}\right) 25-\mathrm{keV}$ monochromatic X-ray 
beam. The projections were recorded with a Hamamatsu Orca Flash sCMOS camera equipped with a $250-\mu m$-thick LuAG scintillator. The complete tomographic scan included 1500 projections, $50 \mathrm{~ms}$ seconds each, for a $180^{\circ}$ rotation. Overall, scan time was approximately $190 \mathrm{~s}$ with samples exposed to the X-ray beam for 75 s. Previous observations have indicated that the duration of scan did not introduce cavitation or injury to the living cells. Tomographic reconstructions were performed using PyHST2 software using the Paganin method (Paganin, 2006), resulting in $1536^{3}$ 32-bit volumetric images. The final spatial resolution was $3.02 \mu^{3}$ per voxel.

Samples of each species were scanned over a range of $\Psi_{\mathrm{x}}$ during the course of dehydration in order to obtain a vulnerability curve to At the conclusion of experiments, all stems and petiole samples were cut $2 \mathrm{~mm}$ above the previously scanned area and scanned again. Vessels where sap was under tension (i.e. functional vessels) immediately filled with air (TorresRuiz et al. 2015b), allowing us to obtain an image showing the entire populations of functional vessels filled with air for deriving the maximum levels of xylem embolism.

\subsection{Dataset for hydraulic segmentation}

The dataset of hydraulic segmentation for woody species was compiled from previously published literature, in which the vulnerability to drought-induced embolism, as represented by $\mathrm{P}_{50}$, for both stem and distal organs (leaf, petiole or midrib) was reported ( $\mathrm{Li}$ and Choat 2020). Values of $\mathrm{P}_{50}$ were either directly obtained from literature or extracted from plots showing vulnerability curves using digitizing software (GetData Graph Digitizer v2.26). In total, 118 cases were collected, including 116 different species and three species with different genotypes (Hevea brasiliensis, Olea europaea and Populus koreana) (Li and Choat 2020). Complied data were separated into two groups based on the methodology used to determine $\mathrm{P}_{50}$ of distal organs. One group specifically includes leaf $\mathrm{P}_{50}\left(\mathrm{P}_{50 \text { leaf }}\right)$ assessed by hydraulic-based techniques, either rehydration kinetics or evaporation flux method. The other group contains petiole or midrib $\mathrm{P}_{50}$ regardless the methods in use, and leaf $\mathrm{P}_{50}$ data measured by non-invasive techniques such as optical visualization or MicroCT. The major difference between these two groups is that the former group represents $\mathrm{P}_{50}$ data measured from whole leaves, and therefore are potentially affected by extra-xylary pathways, while the latter group includes the $\mathrm{P}_{50}$ data measured exclusively from xylem tissues. $\mathrm{P}_{50}$ of distal organs was plotted against stem $\mathrm{P}_{50}$ and hydraulic safety margin was calculated based either on the measurement of whole leaf $\left(\mathrm{HSM}_{\text {leaf }}\right)$ or only xylem $\mathrm{P}_{50}\left(\mathrm{HSM}_{\mathrm{xylem}}\right)$ across species.

\subsection{Data analysis}

Images generated by microCT were processed following the procedure described in Nolf et al. (2017). Briefly, a median Z-
Fig. 1 Transverse section scanned by microCT showing the dynamics of xylem embolism in leaf petioles of $P$. tremula (panels a-c), $B$. pendula (panels e-f), L. tulipifera (panels $\mathbf{g}-\mathbf{i}$ ) and $O$. europaea (panels $\mathbf{j}-\mathbf{l}$ ). Water-filled and embolized conduits appear as light grey and dark, respectively. Values in each panel indicate stem water potentials at which trees were scanned. Scale bars indicate $150 \mu \mathrm{m}$ for all images. Blue and red arrows indicate water-filled and air-filled vessel, respectively

projection of c. $30 \mu \mathrm{m}$ (11 2D cross sections) along the sample axis was extracted from the middle of the scan volumes using imageJ software. Images were segmented to select only airfilled vessels. Vessel separation was aided by the 'Watershed' function (Choat et al. 2016) and, when necessary, manually drawing vessel borders. Air-filled vessel dimensions were measured using the 'ANALYSE PARTICLES' function in ImageJ on all xylem vessels.

Percentage loss of conductivity (PLC, \%) for each stem image was quantified in two ways. We first estimated the percent embolism based on the number of embolized vessels at each water potential $\left(V_{\mathrm{n}}\right)$ relative to the maximum $\left(V_{\max }\right)$, which was considered as the total embolized vessel number after cutting for each individual. Number of embolized vessels was extracted from each image and the PLC, represented by the percentage of embolized vessels, was calculated as $\mathrm{PLC}_{\mathrm{VC}}$ $(\%)=\left(V_{\mathrm{n}} / V_{\max }\right) \times 100$. For petiole images, PLC was quantified by vessel counting because the boundary of some embolized vessels was difficult to identify in some images due to a lack of spatial resolution.

Secondly, the theoretical specific hydraulic conductivity for the embolized vessels $\left(K_{\mathrm{t}}\right)$ was calculated by summing the individual conductivity of all embolized vessel:

$K_{\mathrm{t}}=\sum_{\substack{\text { embolized } \\ \text { vessels }}}\left(\frac{D^{4} \pi}{128 \eta}\right)$

where $D$ is the conduit diameter based on area with the assumption of circularity and $\eta$ is the dynamic viscosity of water (1.002 $10^{-3} \mathrm{~Pa} \cdot \mathrm{s}$ at $\left.20{ }^{\circ} \mathrm{C}\right)$. Then, the maximum theoretical loss of hydraulic conductivity $\left(K_{\max }\right)$ was considered as the $K_{\mathrm{t}}$ of stems and petioles after cutting $2 \mathrm{~mm}$ above the scan zone (see above), i.e. that provides the entire population of functional vessels. PLC based on theoretical hydraulic conductivity $\left(\mathrm{PLC}_{\mathrm{TC}}\right)$ was then estimated as:

$\operatorname{PLC}_{\mathrm{TC}}(\%)=\left(\frac{K_{\mathrm{t}}}{K_{\max }}\right) \times 100$

Organ vulnerability curves (i.e. petiole and stem) were constructed by plotting the PLC data against corresponding stem water potentials given that the difference in water potential is trivial across organs after stomatal closure. For each species, curves for stems and petioles were constructed by combining data from replicate plants, in order to provide PLC and corresponding water potential values over the full range of 

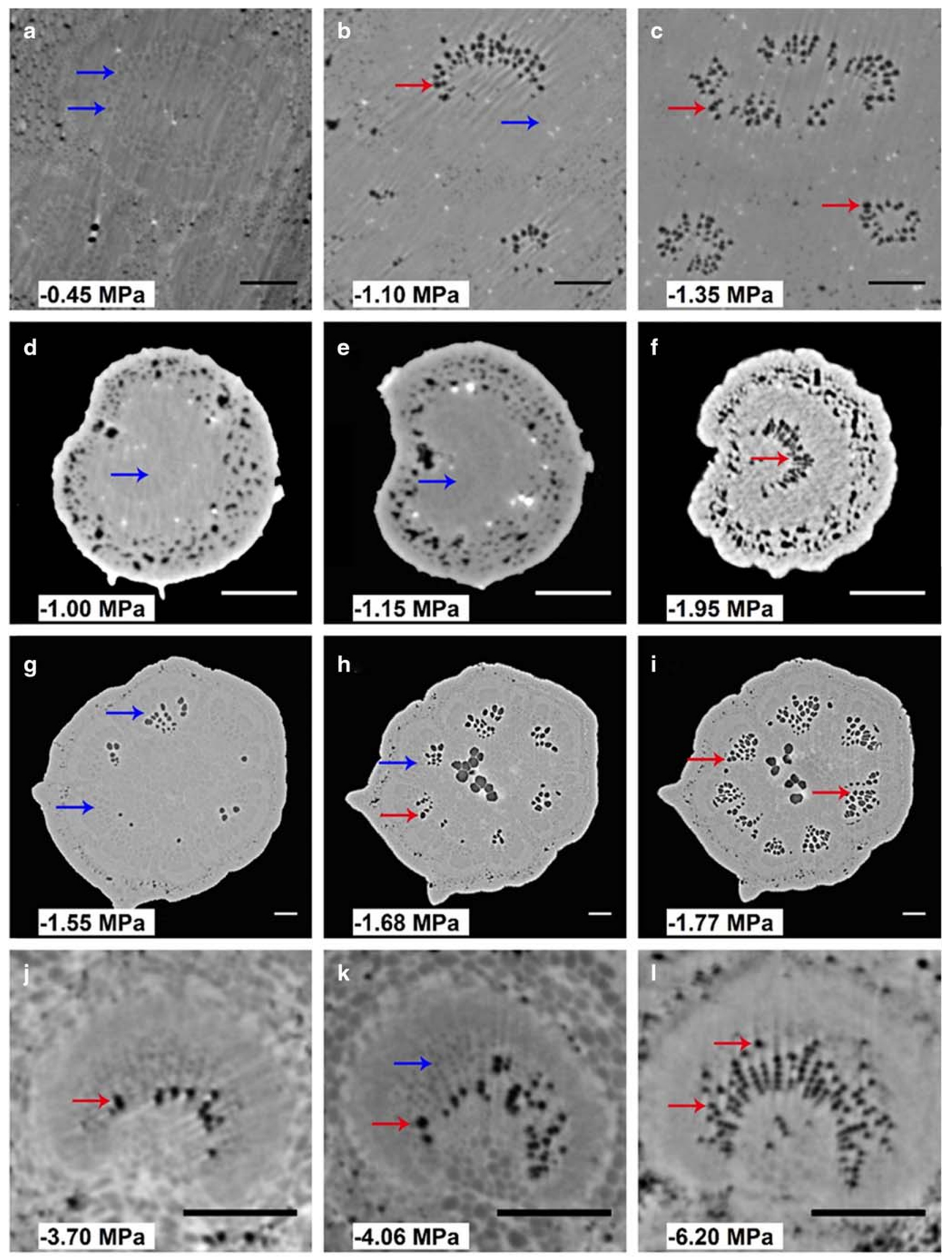

INRAC פ Springst 
vulnerability curves. By doing so, one composite vulnerability curve per organ for each species was generated. Vulnerability curves were then fitted by Weibull function using the fitplc package in $\mathrm{R}$ to obtain $\mathrm{P}_{50}$ and its bootstrap confidence interval (CI) (Duursma and Choat 2017). $\mathrm{P}_{50}$ of petiole and stem was considered significantly different if their CI did not overlap.

\section{Results}

For scans of petiole samples, embolized vessels appeared as dark areas that were readily distinguished from surrounding tissue. The difference between water-filled vessels and surrounding hydrated tissues (e.g. pith) was less discernable due to the lower X-ray contrast (Fig. 1). For stem samples, water-filled vessels and embolized vessels could be easily differentiated, appearing as dark grey and black, respectively (Fig. 2). Additionally, the scans allowed us to differentiate the pattern of embolism across growth rings ata given water potential. It appeared that newly developed vessels (i.e. current year) tended to embolize at more negative water potentials than the older vessels for all species (Figs. 1 and 2).

Estimates of percentage loss of conductivity (PLC) based on vessel counting $\left(\mathrm{PLC}_{\mathrm{VC}}\right)$ and theoretical conductivity ( $\mathrm{PLC}_{\mathrm{TC}}$ ) were very similar for all four species, as evidenced by the clustering of datapoints around the line representing the 1:1 relationship (Fig. 3). Vulnerability curves plotted with $\mathrm{PLC}_{\mathrm{VC}}$ and $\mathrm{PLC}_{\mathrm{TC}}$ yielded nearly identical water potential at $50 \%$ loss of conductivity $\left(\mathrm{P}_{50}\right)$, although the width of confidence interval was higher for $\mathrm{P}_{50}$ based on vessel counting compared with theoretical conductivity in L. tulipifera (Table 1).

For three of the four species (B. pendula, L. tulipifera and O. europaea), native embolism was recorded in stems at water potentials higher than $-1.0 \mathrm{MPa}$ (Fig. 4a, c, d). Nonetheless, it was unlikely that the vulnerability curves were significantly affected, given the levels of native embolism were generally low (below ca. 10\%). For all species investigated, no statistically significant difference was detected for $\mathrm{P}_{50}$ between stems and petioles (Table 1). $\mathrm{P}_{50}$ for petioles and stems were very similar for $B$. pendula. For $L$. tulipifera, $\mathrm{P}_{50}$ of stem was $0.47 \mathrm{MPa}$ higher than that of petiole. The lack of PLC data at more negative water potentials in petioles and stems of $O$. europaea did not allow a precise estimation of the upper bound of CI of $\mathrm{P}_{50}$. Stems of $O$. europaea appeared to be slightly more resistant than petioles. However, the difference between organ $\mathrm{P}_{50}$ was small and their lower bounds of CIs were largely overlapped (Fig. 4, Table 1).

The compiled dataset showed that when vulnerability segmentation is assessed based on the $\mathrm{P}_{50}$ of midrib, petiole or leaf vascular system, many species exhibited small differences in $\mathrm{P}_{50}$ between distal organs and stems, leading to strong
Fig. 2 MicroCT slices showing the dynamics of xylem embolism in stems of $P$. tremula (panels a-c), B. pendula (panels $\mathbf{d}-\mathbf{f}$ ), L. tulipifera (panels $\mathbf{g}-\mathbf{i}$ ) and $O$. europaea (panels $\mathbf{j}-\mathbf{l}$ ) during dehydration. Water-filled and embolized conduits appear as light grey and dark, respectively. Values in each panel indicate stem water potentials at which trees were scanned. Scale bars indicate $150 \mu \mathrm{m}$ for all images. Blue and red arrows indicate waterfilled and air-filled vessel, respectively

convergence in hydraulic safety margin with some divergence from a 1:1 relationship at lower $\mathrm{P}_{50}$ values (Fig. 5; Li and Choat 2020). In contrast, when leaf vulnerability is assessed by methods that incorporate extra-xylary resistance, leaf vulnerability diverges strongly from stem (xylem) vulnerability, especially at more negative water potentials.

\section{Discussion}

Using a non-invasive microCT imaging approach, we observed no evidence of hydraulic vulnerability segmentation between petioles and stems of four angiosperm tree species. By virtue of making measurements on intact plants, we could confirm that little hydraulic segmentation occurred regardless of mechanism, i.e. petioles did not experience significantly higher levels of embolism than adjacent stems during dehydration for any of the species. This result contrasts with a number of previous findings indicating that, within a plant, petioles and leaves are more vulnerable to embolism than stems (Tyree et al. 1993; Choat et al. 2005; Johnson et al. 2011; Bucci et al. 2013; Pivovaroff et al. 2014; Torres-Ruiz et al. 2015a, b; Hochberg et al. 2016). Our data, however, are consistent with the results of recent studies utilizing noninvasive methods, which report no significant difference in vulnerability between leaf and stem xylem across a range of plant functional types (Bouche et al. 2016; Skelton et al. 2017; Rodriguez-Dominguez et al. 2018; Skelton et al. 2018; Losso et al. 2019).

In the present study, vulnerability curves of petioles and stems were constructed using X-ray microCT. A major advantage of this technique is that the dynamics of xylem hydraulic status can be visualized in vivo, avoiding any potential artefacts during sample preparation (Cochard et al. 2013; Choat et al. 2015, 2016) and allowing differences in organ vulnerability to be assessed while plants undergo natural dehydration treatments. However, rather than measuring the reduction in flow rate directly, embolism is quantified by either estimating the theoretical loss of conductivity or calculating the proportion of embolized vessels, both of which involve limitations (Choat et al. 2015; Charrier et al. 2016; Hochberg et al. 2016; Nolf et al. 2017). The Hagen-Poiseuille equation assumes a fourth power relationship between pipe radius and conductive capacity; therefore, minor differences in the 2D geometry of vessels can lead to substantial changes in estimated theoretical conductivity. This error may emerge during image processing 

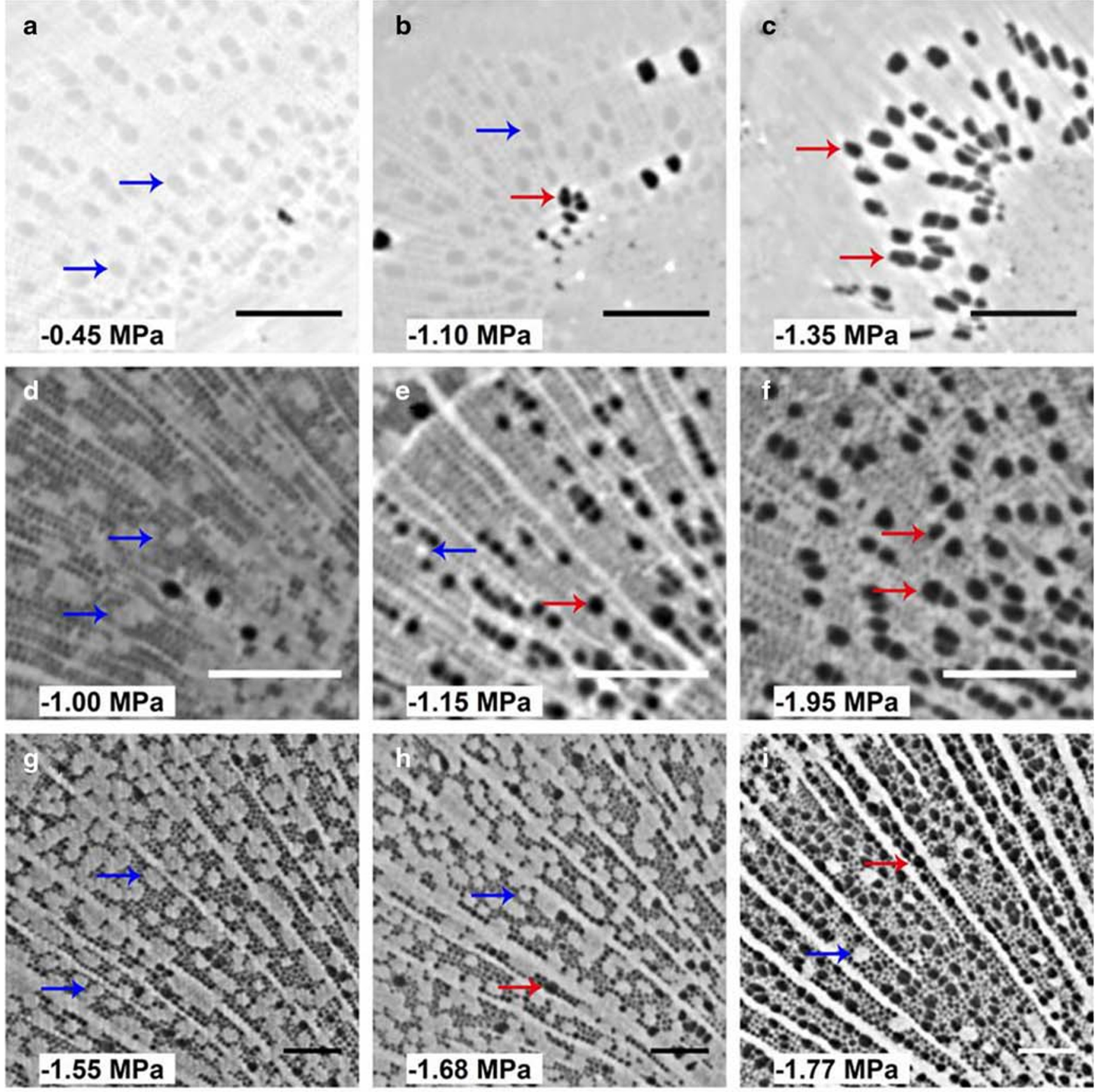

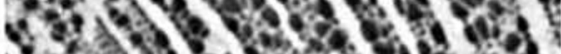

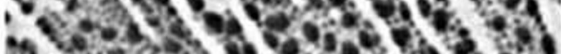

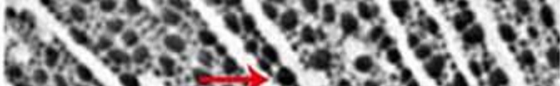

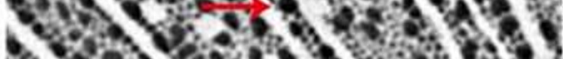
$4200 \%$ \%

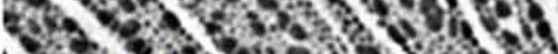

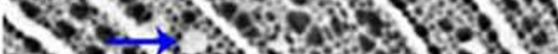

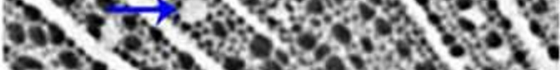
60.250 .25

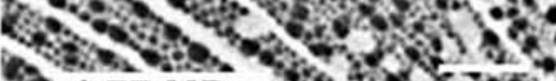

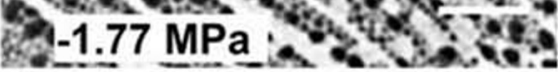
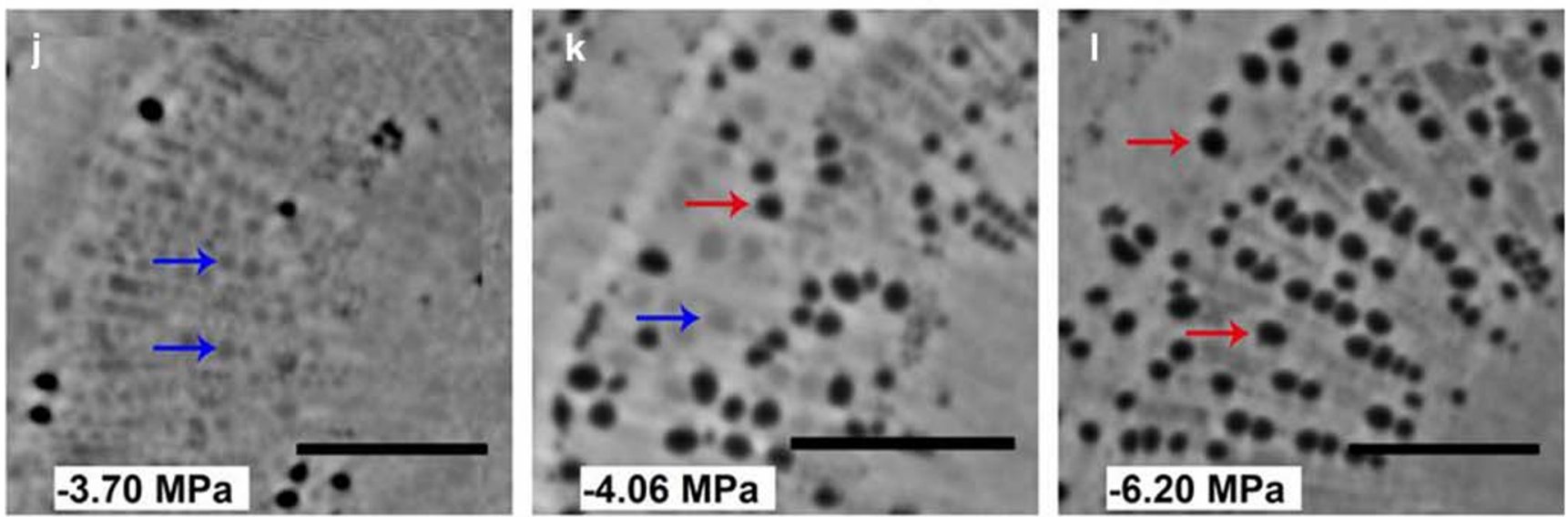
when image-specific thresholds are subjectively assigned to differentiate the water-filled and embolized vessels. By the same principle, calculating PLC by comparing the embolized vessels relative to the total vessels ignores the contribution of different vessel size groups to hydraulic conductivity. This source of error may be trivial for diffuse-porous species with a small range of vessel sizes across the xylem cross section. Consistent with this prediction, we showed that stem vulnerability curves based on theoretical conductivity and vessel counts were comparable, suggesting that both image analysis approaches are applicable to the diffuse-porous species used in this study (Fig. 3). However, more significant errors may be encountered for ring-porous species in which vessel classes differ both in size and vulnerability to embolism (Fukuda et al. 2015).

An implicit assumption of the microCT technique is that all water-filled vessels are functional (Klepsch et al. 2018). It has been suggested that some conduits that appear water-filled in X-ray images may not be conductive because they are immature, blocked by micro substances such as gel or gum, or still isolated from the conducting vessel network (Choat et al. 2016; Jacobsen et al. 2018). In the present study, the cut stem (maximum number of embolized vessels) approach ensured that only vessels connected to the transpiration stream and under tension would be filled by air, while excluding conduits that do not contribute to the maximum conductivity (e.g.

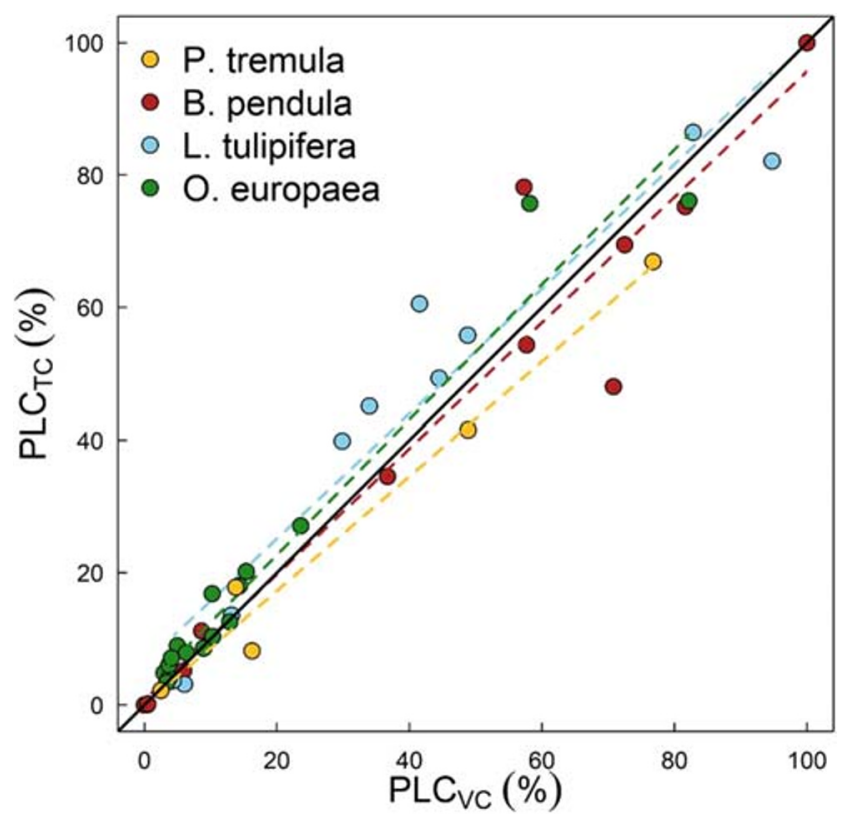

Fig. 3 Comparison of percentage loss of xylem conductivity calculated based on theoretical conductivity $\left(\mathrm{PLC}_{\mathrm{TC}}, \%\right)$ and vessel counting $\left(\mathrm{PLC}_{\mathrm{VC}}, \%\right)$ for stems of four species (P. tremula, yellow; B. pendula, red; L. tulipifera, blue; $O$. europaea, green). Results of linear regression are shown as dashed lines with the same colour. Black solid line indicates 1:1 relationship. Adjusted $R^{2}$ of linear regression for P. tremula, $B$. pendula, L. tulipifera and $O$. europaea are $0.95,0.93,0.91$ and 0.95 , respectively. $p<0.001$ in all cases immature or gel-filled vessels). Previous comparisons of vulnerability curves generated from microCT against traditional hydraulic techniques have shown good agreement between methods. These results suggest errors associated with estimated theoretical conductance from cross sections are generally negligible and that microCT is a reliable method for assessing the xylem vulnerability to embolism (Choat et al. 2016; Nolf et al. 2017; Charrier et al. 2018; Losso et al. 2019). In the current study, the estimated stem $\mathrm{P}_{50}$ for $B$. pendula and L. tulipifera was similar to the values reported in Klepsch et al. (2018) using the flow-centrifuge technique, while stem $\mathrm{P}_{50}$ of P. tremula and $O$. europaea was in good agreement with the values estimated from bench-dehydration (Tognetti et al. 1999; Torres-Ruiz et al. 2013, 2014). Although crosstechnique comparison was not an aim of this study, our data provide additional evidence for the reliability of microCT in assessing xylem vulnerability to embolism.

The key finding of our current study was that petioles are not more vulnerable to embolism than stems in the species studied, leading to rejection of the vulnerability segmentation hypothesis in the four studied species. It is clear that the occurrence of segmentation is not contingent on differences in organ vulnerability since higher levels of embolism may occur in distal organs as a result of water potential gradients developed during transpiration. Despite similar vulnerability, native embolism in terminal organs such as leaves and petioles could still reach critical thresholds for cavitation earlier than stems due to more negative water potential under specific environmental conditions (Yang and Tyree 1994). Studies utilizing non-invasive imaging techniques on intact plants should theoretically account for both vulnerability and pressure gradient mechanisms of segmentation. In our study, plants were dehydrated naturally and allowed to transpire in full sunlight. Given that we did not observe embolism formation in petioles earlier than stems, it is clear that neither mechanism of segmentation occurred. It is possible that hotter and drier

Table 1 Stem water potential inducing $50 \%$ loss of xylem conductivity $\left(\mathrm{P}_{50}, \mathrm{MPa}\right)$ for petiole and stem of three species

\begin{tabular}{llll}
\hline Species & Petiole & \multicolumn{2}{l}{ Stem } \\
\cline { 3 - 4 } & & $\mathrm{P}_{50 \mathrm{VC}}$ & $\mathrm{P}_{50 \mathrm{TK}}$ \\
\hline P. tremula & $1.29[1.02,1.85]$ & $1.36[1.30]$ & $1.40[1.39,1.41]$ \\
B. pendula & $1.83[1.83,1.93]$ & $1.85[1.71,2.00]$ & $1.88[1.71,2.07]$ \\
L. tulipifera & $2.17[1.68,2.29]$ & $1.70[1.41,2.66]$ & $1.52[1.22,1.83]$ \\
O. europaea & $5.34[4.62]$ & $6.07[4.80]$ & $5.74[4.59]$ \\
\hline
\end{tabular}

Numbers in brackets indicate the upper and lower bound of $95 \%$ confidence interval. $P_{50}$ of petioles are estimated by vessel counting, while $P_{50}$ of stem are shown as values based on either vessel counting $\left(\mathrm{P}_{50 \mathrm{VC}}\right)$ or theoretical conductivity $\left(\mathrm{P}_{50 \mathrm{TK}}\right)$. Note that missing upper bound of confidence interval of means values were unable to be estimated precisely due to insufficient datapoints at more negative water potentials 
Fig. 4 Percentage loss of xylem conductivity as a function of stem water potential for petioles (red) and stems (blue) of four angiosperm tree species, (a) Populus tremula, (b) Betula pendula, (c) Liriodendron tulipifera, (d) Olea europaea. Solid lines are fitted curves computed using Weibull function with confidence interval. Red and blue solid and dashed lines indicate water potential induced $50 \%$ loss of conductivity and corresponding upper and lower bound bootstrap confidence interval, respectively

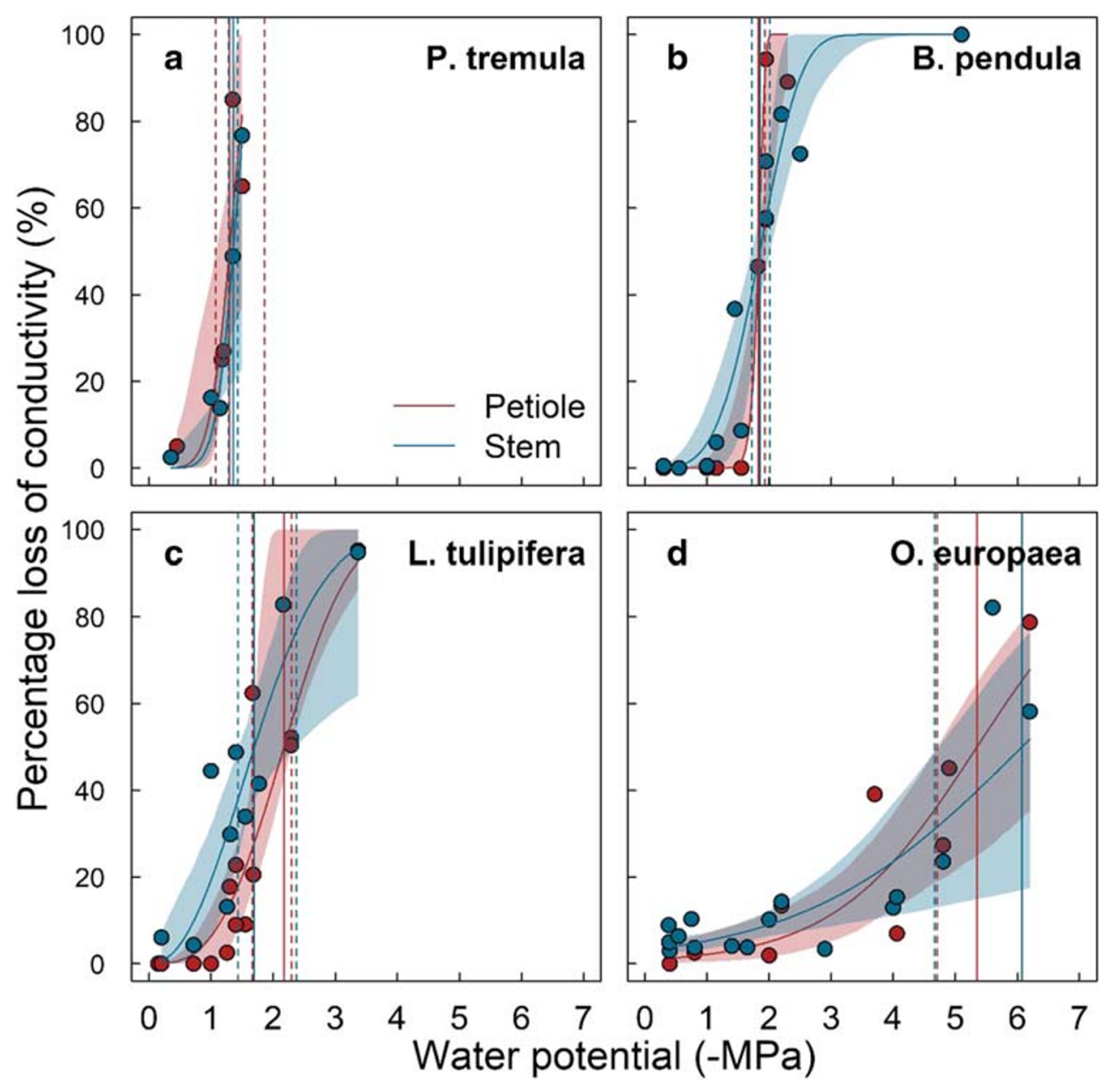

conditions during the summer may lead to the occurrence of higher levels of embolism in leaves and petioles vs. stems due to steeper water potential gradients that would occur with higher levels of transpiration.

Our results contrast with many previous studies examining hydraulic segmentation, which have reported higher vulnerability in distal organs (leaves, petioles) compared with basal organs (branches, trunks). For example, Pivovaroff et al. (2014) reported more vulnerable leaves than stems in 17 species, and recent meta-analyses concluded that leaves generally have less negative $\mathrm{P}_{50}$ than stems within a species (Bartlett et al. 2016; Zhu et al. 2016). However, there are a number of important qualifying factors that must be considered when comparing results from previous work on hydraulic segmentation. When evaluating hydraulic segmentation, studies in which only xylem vulnerability has been measured must be separated from those that incorporate extra-xylary components of the hydraulic pathway (Scoffoni et al. 2017). Studies in which leaf vulnerability has been determined by hydraulic techniques usually incorporate extra-xylary pathways, which lose conductance at higher water potentials than the leaf xylem (Bouche et al. 2016; Scoffoni et al. 2017). For instance, Scoffoni et al. (2017) reported large loss of conductance in extra-xylary pathways before any embolism occurred in the leaf vascular network. Loss of conductance in extraxylary pathways is attributed to changes in membrane permeability and cell shrinkage, factors that presumably allow recovery of conductive capacity on short time scales. In contrast, xylem embolism represents a more permanent reduction in hydraulic capacity, with high levels of embolism linked to death of organs or the whole plant (Rood et al. 2000; Brodribb and Cochard 2009).

When xylem vulnerability is measured separately from extraxylary components, the difference in $\mathrm{P}_{50}$ between stems and distal organs becomes less pronounced. Visual techniques such as microCT and optical visualization provide an opportunity to assess the impacts of embolism in isolation from extra-xylary components, even in more spatially complex tissues of roots and leaves (Losso et al. 2019). Notably, the majority of recent studies using visual techniques have reported no evidence of vulnerability segmentation between stems and leaves. For instance, leaves showed very similar or even more negative $\mathrm{P}_{50}$ compared with stems in some Quercus species when only xylem embolism was accounted for (Skelton et al. 2018). Our results are also consistent with earlier 


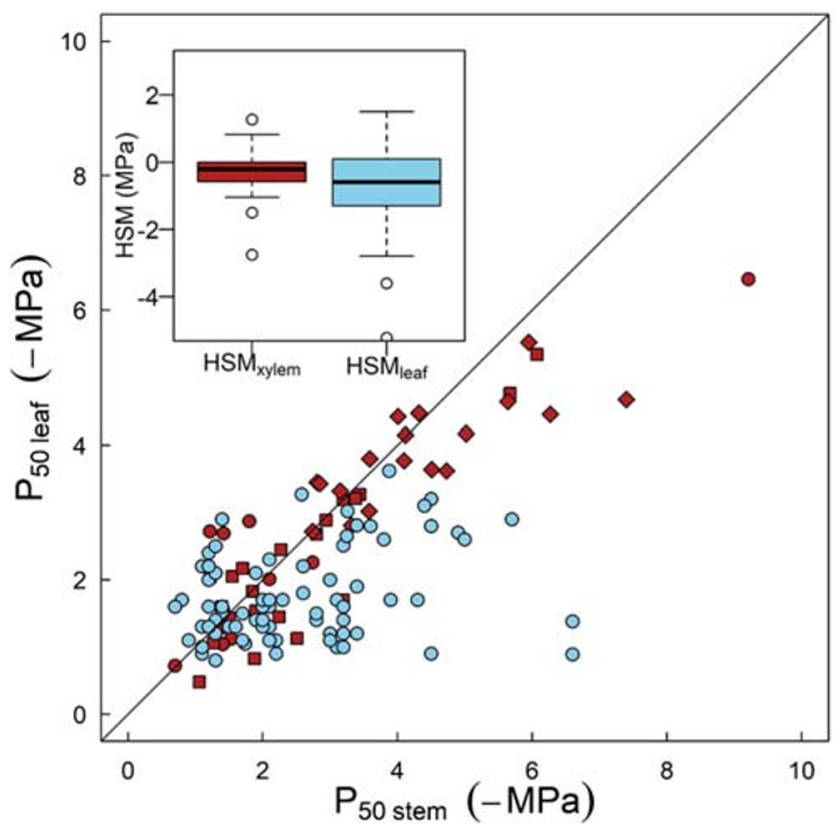

Fig. 5 Water potential threshold inducing $50 \%$ loss of conductivity $\left(\mathrm{P}_{50}\right)$ of stem $\left(\mathrm{P}_{50 \text { stem }}\right)$ plotted against that of leaf $\left(\mathrm{P}_{50 \text { leaf }}\right)$ showing the commonality of vulnerability segmentation across tree species. Data were compiled from published literature in which $\mathrm{P}_{50}$ of different organs were measured on the same set of plants, including the 63 species reported in Zhu et al. (2016). Blue circles indicate $\mathrm{P}_{50 \text { leaf }}$ that was estimated by assessing the dynamics of whole leaves, which incorporate the extra-xylary pathway. Alternatively, $\mathrm{P}_{50 l e a f}$ can be measured from midrib (red circle)/petiole (red square), or exclusively from the xylem network of leaves (e.g. microCT or optical technique), in which only the conductivity of xylem tissues is accounted for (red diamond). The solid line represents the 1:1 relationship. Inset boxplot shows the distribution of hydraulic safety margin (HSM, MPa; defined as $\mathrm{P}_{50 \text { stem }}-\mathrm{P}_{50 \text { leaf }}$ )

studies in which hydraulic techniques were used to evaluate differences in the vulnerability of stem and petiole xylem of temperate tree species (Cochard et al. 1992, 1997). However, even when xylem vulnerability is considered separately from extra-xylary resistance, these patterns are not universal; previous studies have shown that petioles of Vitis vinifera were more vulnerable than stems indicating the vulnerability segmentation occurs for some species (Charrier et al. 2016; Hochberg et al. 2016). Prior comparisons of petiole and stem vulnerability for walnut also provide evidence of vulnerability segmentation and suggest that, in some cases, the petioles act as a hydraulic fuse that proceeds leaf shedding (Tyree et al. 1993).

Taken in context, these results indicate that the degree of xylem hydraulic segmentation between distal and basal organs varies across species, thus suggesting a range of physiological strategies in case of water stress, rather than a universal phenomenon. This is also strongly supported by the complied literature dataset, which showed that xylem of distal organs is not necessarily more vulnerable than stems across a wide range of tree species. The results of our study and this data synthesis demonstrate that (a) xylem vulnerability to embolism is similar between stems and distal organs, and (b) caution should be used in drawing general conclusions regarding hydraulic segmentation without accounting for methodology and the influence of loss in extra-xylary resistance. These conclusions raise obvious questions regarding the functional significance of different components in the hydraulic pathway and the consequences of losing hydraulic conductance in extra-xylary and xylary sections. Distal segmentation effected by loss of extra-xylary resistance may lead to stomatal closure and maintenance of water reservoirs within the leaf (Scoffoni et al. 2017) while the occurrence of xylem embolism is associated with permanent dysfunction and death of distal organs. Elucidating underlying mechanisms of segmentation and the importance of various hydraulic components will require a more detailed assessment of spatial pattern of hydraulic architecture, especially for leaves, in which hydraulic transport is regulated by multiple pathways.

Acknowledgements We thank the PSICHE beamline (SOLEIL synchrotron facility, project 201412229) as well as the Experimental Unit of Pierroton (UE 0570, INRA, 69 route d'Arcachon, 33612 CESTAS, France) for providing the plant material.

Funding information This work was supported by the program "Investments for the Future" (ANR-10-EQPX-16, XYLOFOREST) from the French National Agency for Research. BC was supported by an Australian Research Council Future Fellowship (FT130101115) with travel funding provided by the International Synchrotron Access Program (ISAP) managed by the Australian Synchrotron.

Data availability The datasets generated during and/or analysed during the current study are available in the figshare repository, https://10.6084/ m9.figshare.11948670.v2.

\section{Compliance with ethical standards}

Conflict of interest The authors declare that they have no conflict of interest.

\section{References}

Anderegg WR, Klein T, Bartlett M, Sack L, Pellegrini AF, Choat B, Jansen S (2016) Meta-analysis reveals that hydraulic traits explain cross-species patterns of drought-induced tree mortality across the globe. Proc Natl Acad Sci 113:5024-5029

Barigah TS, Charrier O, Douris M, Bonhomme M, Herbette S, Améglio T, Fichot R, Brignolas F, Cochard H (2013) Water stress-induced xylem hydraulic failure is a causal factor of tree mortality in beech and poplar. Ann Bot 112:1431-1437

Bartlett MK, Klein T, Jansen S, Choat B, Sack L (2016) The correlations and sequence of plant stomatal, hydraulic, and wilting responses to drought. Proc Natl Acad Sci 113:13098-13103

Blackman CJ, Brodribb TJ, Jordan GJ (2009) Leaf hydraulics and drought stress: response, recovery and survivorship in four woody temperate plant species. Plant Cell Environ 32:1584-1595

Bouche PS, Delzon S, Choat B, Badel E, Brodribb TJ, Burlett R, Cochard H, Charra-Vaskou K, Lavigne B, Li S (2016) Are needles of Pinus 
pinaster more vulnerable to xylem embolism than branches? New insights from X-ray computed tomography. Plant Cell Environ 39: 860-870

Brodribb TJ, Cochard H (2009) Hydraulic failure defines the recovery and point of death in water-stressed conifers. Plant Physiol 149:575584

Brodribb TJ, Hill R (1999) The importance of xylem constraints in the distribution of conifer species. New Phytol 143:365-372

Brodribb TJ, Skelton RP, McAdam SA, Bienaimé D, Lucani CJ, Marmottant P (2016) Visual quantification of embolism reveals leaf vulnerability to hydraulic failure. New Phytol 209:1403-1409

Bucci SJ, Scholz FG, Peschiutta ML, Arias NS, Meinzer FC, Goldstein G (2013) The stem xylem of Patagonian shrubs operates far from the point of catastrophic dysfunction and is additionally protected from drought-induced embolism by leaves and roots. Plant Cell Environ 36:2163-2174

Charrier G, Torres-Ruiz JM, Badel E, Burlett R, Choat B, Cochard H, Delmas CE, Domec J-C, Jansen S, King A (2016) Evidence for hydraulic vulnerability segmentation and lack of xylem refilling under tension. Plant Physiol 172:1657-1668

Charrier G, Delzon S, Domec J-C, Zhang L, Delmas CE, Merlin I, Corso D, King A, Ojeda H, Ollat N (2018) Drought will not leave your glass empty: low risk of hydraulic failure revealed by long-term drought observations in world's top wine regions. Sci Adv 4: eaao6969

Choat B, Lahr EC, Melcher PJ, Zwieniecki MA, Holbrook NM (2005) The spatial pattern of air seeding thresholds in mature sugar maple trees. Plant Cell Environ 28:1082-1089

Choat B, Brodersen CR, McElrone AJ (2015) Synchrotron X-ray microtomography of xylem embolism in Sequoia sempervirens saplings during cycles of drought and recovery. New Phytol 205:10951105

Choat B, Badel E, Burlett R, Delzon S, Cochard H, Jansen S (2016) Noninvasive measurement of vulnerability to drought-induced embolism by X-ray microtomography. Plant Physiol 170:273-282

Choat B, Nolf M, Lopez R, Peters JM, Carins-Murphy MR, Creek D, Brodribb TJ (2018) Non-invasive imaging shows no evidence of embolism repair after drought in tree species of two genera. Tree Physiol 39:113-121

Cochard H, Cruiziat P, Tyree MT (1992) Use of positive pressures to establish vulnerability curves: further support for the air-seeding hypothesis and implications for pressure-volume analysis. Plant Physiol 100:205-209

Cochard H, Peiffer M, Le Gall K, André G (1997) Developmental control of xylem hydraulic resistances and vulnerability to embolism in Fraxinus excelsior L.: impacts on water relations. J Exp Bot 48: $655-663$

Cochard H, Badel E, Herbette S, Delzon S, Choat B, Jansen S (2013) Methods for measuring plant vulnerability to cavitation: a critical review. J Exp Bot 64:4779-4791

Corso D, Delzon S, Lamarque LJ, Cochard H, Torres-Ruiz JM, King A, Brodribb TJ (2020) Neither xylem collapse, cavitation or changing leaf conductance drive stomatal closure in wheat. Plant Cell Environ. https://doi.org/10.1111/pce.13722

Delzon S, Douthe C, Sala A, Cochard H (2010) Mechanism of waterstress induced cavitation in conifers: bordered pit structure and function support the hypothesis of seal capillary-seeding. Plant Cell Environ 33:2101-2111

Dixon HH, Joly J (1895) XII. On the ascent of sap. 186: 563-576

Duursma RA, Choat B (2017) fitplc: an R package to fit hydraulic vulnerability curves. Journal Of Plant Hydraulics 4. https://doi.org/10. 20870/jph.2017.e002

Engelbrecht BM, Comita LS, Condit R, Kursar TA, Tyree MT, Turner BL, Hubbell SP (2007) Drought sensitivity shapes species distribution patterns in tropical forests. Nature 447:80-82
Fukuda K, Kawaguchi D, Aihara T, Ogasa MY, Miki NH, Haishi T, Umebayashi T (2015) Vulnerability to cavitation differs between current-year and older xylem: non-destructive observation with a compact magnetic resonance imaging system of two deciduous diffuse-porous species. Plant Cell Environ 38:2508-2518

Hochberg U, Albuquerque C, Rachmilevitch S, Cochard H, DavidSchwartz R, Brodersen CR, McElrone A, Windt CW (2016) Grapevine petioles are more sensitive to drought induced embolism than stems: evidence from in vivo MRI and microcomputed tomography observations of hydraulic vulnerability segmentation. Plant Cell Environ 39:1886-1894

Hubbard R, Ryan M, Stiller V, Sperry J (2001) Stomatal conductance and photosynthesis vary linearly with plant hydraulic conductance in ponderosa pine. Plant Cell Environ 24:113-121

Jacobsen AL, Valdovinos-Ayala J, Pratt RB (2018) Functional lifespans of xylem vessels: development, hydraulic function, and postfunction of vessels in several species of woody plants. Am J Bot 105:142-150

Johnson D, McCulloh KA, Meinzer F, Woodruff D, Eissenstat D (2011) Hydraulic patterns and safety margins, from stem to stomata, in three eastern US tree species. Tree Physiol 31:659-668

Johnson DM, Wortemann R, McCulloh KA, Jordan-Meille L, Ward E, Warren JM, Palmroth S, Domec J-C (2016) A test of the hydraulic vulnerability segmentation hypothesis in angiosperm and conifer tree species. Tree Physiol 36:983-993

Klepsch M, Zhang Y, Kotowska MM, Lamarque LJ, Nolf M, Schuldt B, Torres-Ruiz JM, Qin DW, Choat B, Delzon S (2018) Is xylem of angiosperm leaves less resistant to embolism than branches? Insights from microCT, hydraulics, and anatomy. J Exp Bot 69: $5611-5623$

Lamarque LJ, Corso D, Torres-Ruiz JM, Badel E, Brodribb TJ, Burlett R, Charrier G, Choat B, Cochard H, Gambetta GA (2018) An inconvenient truth about xylem resistance to embolism in the model species for refilling Laurus nobilis L. Ann For Sci 75:88

Li X, Choat B (2020) Vulnerability to embolism and hydraulic segmentation. figshare. [Dataset]. https://doi.org/10.6084/m9.figshare. 11948670.v2. Accessed 6 March 2020

Losso A, Bär A, Dämon B, Dullin C, Ganthaler A, Petruzzellis F, Savi T, Tromba G, Nardini A, Mayr S (2019) Insights from in vivo microCT analysis: testing the hydraulic vulnerability segmentation in Acer pseudoplatanus and Fagus sylvatica seedlings. New Phytol 221: $1831-1842$

Nolf M, Creek D, Duursma R, Holtum J, Mayr S, Choat B (2015) Stem and leaf hydraulic properties are finely coordinated in three tropical rain forest tree species. Plant Cell Environ 38:2652-2661

Nolf M, Lopez R, Peters JM, Flavel RJ, Koloadin LS, Young IM, Choat B (2017) Visualization of xylem embolism by X-ray microtomography: a direct test against hydraulic measurements. New Phytol 214:890-898

Oliveira RS, Costa FR, van Baalen E, de Jonge A, Bittencourt PR, Almanza Y, Barros FV, Cordoba EC, Fagundes MV, Garcia S (2019) Embolism resistance drives the distribution of Amazonian rainforest tree species along hydro-topographic gradients. New Phytol 221:1457-1465

Pivovaroff AL, Sack L, Santiago LS (2014) Coordination of stem and leaf hydraulic conductance in southern California shrubs: a test of the hydraulic segmentation hypothesis. New Phytol 203:842-850

Rodriguez-Dominguez CM, Carins Murphy MR, Lucani C, Brodribb TJ (2018) Mapping xylem failure in disparate organs of whole plants reveals extreme resistance in olive roots. New Phytol 218:10251035

Rood SB, Patiño S, Coombs K, Tyree MT (2000) Branch sacrifice: cavitation-associated drought adaptation of riparian cottonwoods. Trees 14:248-257

Sack L, Holbrook NM (2006) Leaf hydraulics. Annu Rev Plant Biol 57: 361-381 
Scoffoni C, Albuquerque C, Brodersen CR, Townes SV, John GP, Bartlett MK, Buckley TN, McElrone AJ, Sack L (2017) Outside-xylem vulnerability, not xylem embolism, controls leaf hydraulic decline during dehydration. Plant Physiol 173:1197-1210

Skelton RP, Brodribb TJ, Choat B (2017) Casting light on xylem vulnerability in an herbaceous species reveals a lack of segmentation. New Phytol 214:561-569

Skelton RP, Dawson TE, Thompson SE, Shen Y, Weitz AP, Ackerly D (2018) Low vulnerability to xylem embolism in leaves and stems of North American oaks. Plant Physiol 177:1066-1077

Sperry JS, Tyree MT (1988) Mechanism of water stress-induced xylem embolism. Plant Physiol 88:581-587

Tognetti R, Longobucco A, Raschi A (1999) Seasonal embolism and xylem vulnerability in deciduous and evergreen Mediterranean trees influenced by proximity to a carbon dioxide spring. Tree Physiol 19: 271-277

Torres-Ruiz JM, Diaz-Espejo A, Morales-Sillero A, Martín-Palomo M, Mayr S, Beikircher B, Fernández J (2013) Shoot hydraulic characteristics, plant water status and stomatal response in olive trees under different soil water conditions. Plant Soil 373:77-87

Torres-Ruiz JM, Cochard H, Mayr S, Beikircher B, Diaz-Espejo A, Rodriguez-Dominguez CM, Badel E, Fernandez JE (2014) Vulnerability to cavitation in Olea europaea current-year shoots: further evidence of an open-vessel artifact associated with centrifuge and air-injection techniques. Plant Physiol 152:465-474

Torres-Ruiz JM, Diaz-Espejo A, Perez-Martin A, Hernandez-Santana V (2015a) Role of hydraulic and chemical signals in leaves, stems and roots in the stomatal behaviour of olive trees under water stress and recovery conditions. Tree Physiol 35:415-424

Torres-Ruiz JM, Jansen S, Choat B, McElrone AJ, Cochard H, Brodribb TJ, Badel E, Burlett R, Bouche PS, Brodersen CR (2015b) Direct X- ray microtomography observation confirms the induction of embolism upon xylem cutting under tension. Plant Physiol 167:40-43

Trifilo P, Raimondo F, Lo Gullo MA, Barbera PM, Salleo S, Nardini A (2014) Relax and refill: xylem rehydration prior to hydraulic measurements favours embolism repair in stems and generates artificially low PLC values. Plant Cell Environ 37:2491-2499

Trueba S, Pouteau R, Lens F, Feild TS, Isnard S, Olson ME, Delzon S (2017) Vulnerability to xylem embolism as a major correlate of the environmental distribution of rain forest species on a tropical island. Plant Cell Environ 40:277-289

Tyree MT, Ewers FW (1991) The hydraulic architecture of trees and other woody plants. New Phytol 119:345-360

Tyree M, Cochard H, Cruiziat P, Sinclair B, Ameglio T (1993) Droughtinduced leaf shedding in walnut: evidence for vulnerability segmentation. Plant Cell Environ 16:879-882

Urli M, Porté AJ, Cochard H, Guengant Y, Burlett R, Delzon S (2013) Xylem embolism threshold for catastrophic hydraulic failure in angiosperm trees. Tree Physiol 33:672-683

Yang S, Tyree MT (1994) Hydraulic architecture of Acer saccharum and A. rubrum: comparison of branches to whole trees and the contribution of leaves to hydraulic resistance. J Exp Bot 45:179-186

Zhu SD, Liu H, Xu QY, Cao KF, Ye Q (2016) Are leaves more vulnerable to cavitation than branches? Funct Ecol 30:1740-1744

Zimmermann MH (1983) Xylem structure and the ascent of sap. Springer Science \& Business Media, Berlin

Publisher's note Springer Nature remains neutral with regard to jurisdictional claims in published maps and institutional affiliations.

\section{Affiliations}

\section{Ximeng $\mathrm{Li}^{1}$ - Sylvain Delzon ${ }^{2} \cdot$ Jose Torres-Ruiz ${ }^{3} \cdot$ Eric Badel $^{3} \cdot$ Regis Burlett $^{4} \cdot$ Hervé Cochard $^{3} \cdot$ Steven Jansen $^{5}$. Andrew King ${ }^{6} \cdot$ Laurent J. Lamarque $^{4} \cdot$ Nicolas Lenoir $^{2} \cdot$ Nicolas Martin St-Paul $^{3} \cdot$ Brendan Choat $^{1}$}

1 Hawkesbury Institute for the Environment, Western Sydney University, Locked Bag 1797, Penrith, NSW 2751, Australia

2 INRA, BIOGECO, Univ. Bordeaux, 33615 Pessac, France

3 INRA, PIAF, Université Clermont-Auvergne, 63000 ClermontFerrand, France
4 BIOGECO, INRA, Université de Bordeaux, Pessac, France

5 Ulm University, Institute of Systematic Botany and Ecology, AlbertEinstein-Allee 11, 89081 Ulm, Germany

6 Synchrotron SOLEIL, L'Orme de Merisiers, Saint-Aubin-BP48, 91190 Gif-sur-Yvette Cedex, France 